\title{
A FEMINIZAÇÃO DA VIOLÊNCIA CONTRA O IDOSO E AS DELEGACIAS DE POLÍCIA
}

\author{
Guita Grin Debert ${ }^{1}$ \\ e Amanda Marques de Oliveira ${ }^{2}$
}

\begin{abstract}
RESUMO
A violência contra o idoso é considerada violação dos direitos humanos, e o Brasil tem se empenhado em garantir os direitos dos mais velhos. Com o interesse de discutir os dilemas envolvidos nas iniciativas adotadas no país, o artigo analisa como as agressões contra homens e mulheres mais velhos são tratadas pela polícia, revelando a desconexão entre a imagem que os policiais têm da velhice e o idoso que de fato recorre à polícia. 0 argumento central é que essa desconexão leva à invisibilidade da violência perpetrada, à feminização da velhice e à consideração de que os crimes são fruto de um déficit da moral familiar. A dinâmica do funcionamento das delegacias as transforma em instâncias voltadas à judicialização das relações na família, e o idoso, de sujeito de direitos, passa a ser objeto da violência familiar.
\end{abstract}

Palavras-chave: Velhice. Violência. Delegacias especiais de polícia. Gênero.

\section{THE FEMINIZATION OF VIOLENCE AGAINST THE ELDERLY AND THE POLICE STATIONS}

\section{ABSTRACT}

Violence against the elderly is considered a violation of human rights, and Brazil has been making every effort to guarantee the rights of elderly people. In order to discuss the quandaries related to the initiative taken in the country, the article analyzes how violent acts against elderly men and women are handled by the police, revealing a disconnection

1 Professora Titular do Departamento de Antropologia da Universidade Estadual de Campinas; Pesquisadora do CNPq e do Núcleo de Estudos de Gênero Pagu/UNICAMP, Brasil. ggdebert@uol.com.br ${ }^{2}$ Doutoranda em Ciências Sociais. Universidade Estadual de Campinas. Brasil. a_marques_o@yahoo.com.br 
between how police officers see old age and the elderly who, in fact, resort to the police. The main argument is that this disconnection leads to the invisibility of perpetrated violence, to the feminization of old age, and to the assumption that crimes are a result of a deficit of family morality. The operation dynamics of police stations turn them into venues focused on the judicial settlement of family relations, and the elderly, subject of rights, become the object of family violence.

Keywords: Old Age. Violence, Special Police Units. Gender.

$\mathrm{N}$

a Segunda Assembleia Mundial das Nações Unidas sobre o Envelhecimento, realizada em Madrid, em 2002, objetivando desenvolver uma política internacional de envelhecimento para o século XXI, foi adotado um Plano de Ação Internacional sobre o Envelhecimento no qual a violência contra 0 idoso passou a ser considerada uma violação de direitos humanos.

Esse era um tema ausente da primeira Assembleia, ocorrida em 1982, em Viena, e a colocação da violência contra o idoso no contexto dos direitos humanos estimulou a elaboração de pesquisas empenhadas em identificar dimensões variadas do problema, bem como a proposição de políticas públicas voltadas para a velhice.

A transformação da violência num problema social põe em jogo múltiplas dimensões que vão desde a definição de quem é propriamente o idoso vítima da violência, passando pela caracterização das manifestações do que poderiam ser consideradas ações violentas, até o estabelecimento de quais são as instituições e os agentes encarregados de combatê-la. ${ }^{3}$

Dos planos internacionais não está ausente 0 reconhecimento dos problemas relacionados com o caráter necessariamente universalista dos valores e significados envolvidos em suas propostas e do fato de que o envelhecimento é uma construção histórica, social e cultural específica que deve ser contemplada de modo que as ações recomendadas tenham sucesso. Por essa razão, um amplo debate sobre direitos diferenciados e políticas de reconhecimento tem marcado as reflexões sobre os desafios da igualdade e da democracia. Os próprios órgãos regionais ligados às Nações Unidas, por reconhecerem a grande diversidade do processo de envelhecimento, elaboraram estratégias para a implementação do Plano de Madri que levassem em conta as especificidades regionais.

A definição utilizada com maior frequência nas políticas públicas e nas pesquisas sobre o tema é a adotada pelas Action on Elder Abuse ${ }^{4}$ - e também pela Organização

\footnotetext{
${ }^{3}$ Sobre violência e insulto moral ver Cardoso de Oliveira (2008); sobre a administração da violência ver Kant de Lima et al. (2001) e Rifiotis e Castelnuovo (2011).

${ }^{4}$ Disponível em: www.elderabuse.org.uk
} 
Mundial da Saúde e pela Rede Internacional para a Prevenção de Abusos contra o Idoso - que considera o maltrato contra o idoso "um ato (único ou repetido) ou omissão de ações apropriadas que cause dano ou aflição e que se produz em qualquer relação na qual exista expectativa de confiança."

Internacionalmente foram também construídas categorias e tipologias de modo a criminalizar as várias formas de violência contra a população idosa, que passaram a ser definidas como abuso e negligência, como por exemplo: abuso físico (maus-tratos físicos ou violência física que se referem ao uso da força física), abuso psicológico (maus-tratos psicológicos), abuso sexual e abandono.

No Brasil, a criação de agências de combate à violência contra os idosos antecedeu a conferência de Madri de 2002. Delegacias de polícia de proteção aos idosos, SOSs, o Grupo de Atuação Especial para a Proteção ao Idoso no Ministério Público (GAEPI, em São Paulo) foram criados ainda na década de 1990.

Considerando que as políticas públicas tendem a construir e consagrar representações muito específicas de seu público alvo, o objetivo deste artigo é discutir a complicada trama de questões e demandas relativas ao combate da violência contra homens e mulheres idosos. Com essa finalidade, começamos por indicar o conjunto de razões acionadas para explicar o processo de transformação do envelhecimento numa questão social, dos idosos numa minoria desprivilegiada e os problemas que a heterogeneidade no interior do segmento idoso da população acarreta na definição de políticas públicas para a velhice. Em seguida, apresentamos um quadro dos dilemas envolvidos no atendimento dos idosos nas delegacias de polícia. Interessa mostrar 0 modo pelo qual, no processo de criminalização, a violência contra 0 idoso passa a ser vista como mais uma manifestação da violência doméstica. A tendência observada é, por um lado, feminizar as vítimas e, por outro, considerar que as causas do crime são de caráter moral, resultados da incapacidade dos membros da família de assumir os diferentes papéis que devem ser desempenhados em cada uma das etapas do ciclo da vida familiar. Instituições criadas para politizar a justiça na defesa das minorias correm, assim, o risco de atuarem como operadoras de uma judicialização das relações sociais.

\footnotetext{
${ }^{5}$ Tradução livre: "A single or repeated act or lack of appropriate action, occurring within any relationship where there is an expectation of trust, which causes harm or distress to an older person." Disponível em: www.elderabuse.org.uk

${ }^{6}$ Para maiores detalhes ver Observatório Nacional do Idoso, que é uma iniciativa da Secretaria Especial de Direitos Humanos da Presidência da República em parceria com o Centro Latino-Americano de Estudos de Violência e Saúde Jorge Careli, da Escola Nacional de Saúde Pública - Fundação Oswaldo Cruz e também o Portal do Envelhecimento do Núcleo de Estudo e Pesquisa do Envelhecimento (Nepe), da Pontifícia Universidade Católica de São Paulo, em www.portaldoenvelhecimento.org.br.
} 


\section{Políticas PÚBliCAS E AS MÚLTIPLAS FACES DA VELHICE}

Discorrer sobre a velhice é abordar um assunto que até muito recentemente era visto como uma questão própria da esfera privada e familiar, uma questão de previdência individual ou de associações filantrópicas. Com a transformação do envelhecimento em uma questão social, um conjunto de orientações e intervenções, muitas vezes contraditório, é definido e implementado pelo aparelho de Estado e outras organizações privadas. Um campo de saber específico - a Gerontologia - é criado com profissionais encarregados de compreender e definir os problemas que afetam os velhos e promover a formação de outros especialistas nessa área de estudos. Como consequência desse movimento próprio da forma como os estados modernos classificam e hierarquizam suas populações, que Foucault (1977) denomina como biopoder, tentativas de homogeneização das representações sobre esse segmento populacional são acionadas e uma nova categoria cultural é produzida: os idosos, como um conjunto autônomo e coerente que impõe outro recorte à geografia social, autorizando a colocação em prática de modos específicos de gestão do envelhecimento.

A representação do avanço da idade como um processo contínuo de perdas - em que os indivíduos ficariam relegados a uma situação de abandono, de desprezo e de ausência de papéis sociais - acompanha o processo de constituição da velhice numa preocupação social e política. Essa visão de uma experiência homogênea de perdas funda a Gerontologia e é um elemento de legitimação de direitos sociais que levaram à universalização da aposentadoria, ao conjunto de leis protetivas dos idosos e às conferências e aos planos de ação internacionais para o envelhecimento.

A transformação da velhice em problema social não pode ser compreendida como o resultado mecânico de uma mudança na demografia. Como mostrou Remi Lenoir (1989), um problema social é uma construção social e não o puro resultado do mau funcionamento da sociedade. A constituição de um problema social supõe um trabalho em que, segundo esse autor, estão envolvidas quadro dimensões: reconhecimento, legitimação, pressão e expressão.

0 reconhecimento implica tornar visível uma situação particular. É a conquista de uma atenção pública, e supõe a ação de grupos socialmente interessados em produzir uma nova categoria de percepção do mundo social, a fim de agir sobre ele. A legitimação não é consequência automática do reconhecimento público do problema. Ao contrário, ela supõe o esforço para promovê-lo e inserí-lo no campo das preocupações sociais do momento.

Em outras palavras, às transformações objetivas, sem as quais um problema social não teria sido colocado, soma-se um trabalho específico de enunciação e de formulação pública, ou seja, uma empresa de mobilização capaz de promover sua integração às preocupações do momento e incorporá-lo como objeto de luta política. 
No caso da transformação da velhice em problema social, essa questão é, segundo Lenoir, especialmente importante. Diferentemente de outras categorias, os velhos não dispõem de meios sociais nem de instrumentos de acesso à expressão pública. Os representantes que se colocam como porta-vozes das pessoas idosas são, atualmente, "experts", cuja competência é oficialmente reconhecida pela referência a uma especialidade científica: a Gerontologia. .

As formas de pressão se traduzem em formas de expressão que consagram determinadas convenções sobre a velhice, período que é, certamente, o estágio mais longo da vida.

Os primeiros estudos sobre esse segmento populacional caracterizavam a velhice como uma situação marcada pela decadência física e perdas de papéis sociais, posto que as sociedades modernas não previam um papel específico ou uma atividade para os velhos, abandonando-os a uma existência sem significado. Nessa mesma linha, os velhos eram tidos como uma minoria desprivilegiada nas sociedades industrializadas baixa renda e baixo status seriam o destino inevitável daqueles que atingem os 60 anos, e, nesse sentido, seriam uma minoria estigmatizada como qualquer outra e formariam um grupo com um estilo próprio de vida que se sobrepõe às diferenças de ocupação, sexo, religião e identidade étnica.

Os estudos realizados a partir dos anos de 1970 procuraram caracterizar a diversidade no interior deste segmento, chamando a atenção para a heterogeneidade das experiências de envelhecimento no que diz respeito particularmente às diferenças socioeconômicas, étnicas, de gênero e de religião, mostrando como essas clivagens sociais levam a formas e experiências de discriminação e estigma distintas .

Uma nova face da velhice emerge a partir desses estudos. Contra a visão da velhice como uma situação de perdas e os estereótipos negativos sobre a velhice que ela reproduzia, os gerontólogos procuraram realçar os ganhos que o envelhecimento traz. Dessa perspectiva, os estágios mais avançados da vida passam a ser tratados como momentos privilegiados para novas conquistas guiadas pela busca do prazer, da satisfação e da realização pessoal. As experiências vividas e os saberes acumulados propiciariam aos mais velhos oportunidades de explorar novas identidades, realizar projetos abandonados em outras etapas da vida, estabelecer relações mais profícuas com o mundo dos mais jovens e dos mais velhos. Essas novas imagens acompanham a

\footnotetext{
${ }^{7}$ Diferentemente do que ocorre com a aposentadoria em que o sindicato e o movimento operário têm um papel central na definição e no estabelecimento dos direitos do aposentado. Sobre o movimento dos aposentados ver Simões (2004).

${ }^{8}$ Sobre gênero e classe social ver Motta (1999). Ver ainda o dossiê organizado pela autora sobre Gênero e Velhice, publicado na Revista de Estudos Feministas, v. 5, n. 1, 1997.
} 
construção da "terceira idade" como uma etapa gratificante e abrem espaço para que experiências de envelhecimento bem-sucedidas possam ser vividas coletivamente."

No Brasil, a terceira idade é uma expressão que com muita rapidez se popularizou como uma forma de tratamento das pessoas de mais idade. Nos últimos anos, tem crescido o número de grupos de convivência de idosos e de universidades para a terceira idade que marcam presença mesmo em municípios em que a população idosa é relativamente pequena. Com uma capacidade de mobilização impressionante essas iniciativas têm promovido de maneira muito evidente a redefinição de valores, atitudes e comportamentos dos grupos mobilizados. Debert (1999), ao analisar essa nova face da velhice, aponta para o processo de reprivatização nela implicado. A imagem da terceira idade bem-sucedida não oferece instrumentos capazes de enfrentar os problemas envolvidos na perda de habilidades cognitivas e dos controles físicos e emocionais que estigmatizam o velho e que são fundamentais, na nossa sociedade, para que um indivíduo seja reconhecido como um ser autônomo, capaz de um exercício pleno dos direitos de cidadania. A velhice se transforma num problema de consumidores que falharam porque não souberam se envolver em atividades motivadoras e adotar estilos de vida e formas de consumo capazes de evitar ou retardar a velhice.

A preocupação com a violência contra 0 idoso, bem como a reivindicação por políticas públicas para o seu combate exigem, certamente, uma revisão desta percepção glamorosa das etapas mais avançadas da vida.

Para alguns autores, a visão da velhice como uma situação de perdas e dependência foi substituída por uma visão mais positiva do envelhecimento. É, no entanto, preciso atentar para a coexistência dessas faces distintas da velhice e para 0 modo através do qual as políticas públicas consagram uma ou outra dessas faces.

Em outras palavras, num artigo sobre as narrativas da velhice nas políticas públicas, Simon Biggs (2001) opõe a visão da velhice como uma situação caracterizada pela ausência de produtividade e dependência crescente, que organiza as políticas que prevaleceram na Inglaterra nos anos do governo Thatcher, às políticas do governo Blair, em que as iniciativas voltadas para promover um envelhecimento ativo celebram os atributos positivos da velhice. Em nome da inclusão e da igualdade de oportunidades, esses atributos promovem um ideal de produtividade, desconhecendo os limites que a velhice impõe e a diversidade no interior desse segmento da população.

Considerar que as políticas públicas não são apenas respostas aos problemas sociais, mas são ativas na produção de convenções sobre a definição de seu público alvo, exige um olhar atento para o modo como concepções muito distintas do que é a velhice podem conviver em um mesmo contexto nacional e dar dinâmicas distintas ao

${ }^{9}$ Sobre a constituição da terceira idade, ver Laslett, 1987. 
funcionamento de diferentes instituições. Isso pode ser percebido, também, no modo como as políticas públicas de combate à violência contra mulheres e homens idosos se articularam no contexto brasileiro, como veremos a seguir.

\section{A TRANSFORMAÇÃO DA VIOLÊNCIA CONTRA O IDOSO EM VIOLÊNCIA DOMÉSTICA}

Como já dissemos, a criação de agências de combate à violência contra os idosos no Brasil antecedeu a conferência de Madri de 2002, que estabeleceu como um dos temas do Plano de Ação Internacional para o Envelhecimento o combate às formas de violência. Dentre as experiências pioneiras no Brasil, voltadas para essa questão temos os exemplos das delegacias especializadas e dos grupos especializados do Ministério Público. Em São Paulo, o Grupo de Atuação Especial de Proteção ao Idoso (GAEPI) do Ministério Público data de 1997, e a atuação desse Grupo só pode ser entendida como fruto das mudanças ocorridas no Ministério Público com a Constituição de 1988, pois é a partir dela que a defesa de interesses metaindividuais e a tutela dos interesses difusos e coletivos passam a integrar as atribuições dessa instituição. A criação do GAEPI é fruto da atuação de outro grupo do Ministério Público, o GAPI (Grupo de Atuação de Proteção ao Idoso), e originalmente tinha como responsabilidade reprimir os crimes contra os idosos institucionalizados, ou seja, aqueles que se encontravam em clínicas ou asilos. As dificuldades na investigação desses tipos de casos, bem como a ausência de infraestrutura e formato adequados para 0 encaminhamento de tais denúncias estiveram entre os fatores que levaram à criação do grupo. No entanto, quando em funcionamento, o grupo se surpreendeu ao constatar que não era somente dentro das instituições que os idosos sofriam abusos, mas também dentro das próprias famílias. Assim, o grupo acabou por concentrar boa parte de suas atividades no tratamento de crimes cometido por familiares de idosos (JUVÊNCIO; BAPTISTA, 1994; DEBERT, 2001; DEBERT; OLIVEIRA, 2009).

Nos últimos anos, o interesse na criação de serviços específicos para os idosos tem sido renovado, incluindo as delegacias, defensorias e promotorias públicas especializadas no atendimento de pessoas nessa faixa de idade, bem como SOSs Idoso. Em quase todos os estados, foram constituídas as chamadas "Promotorias de Defesa da Pessoa com Deficiência e Idosos". No Ministério Público a AMPID - Associação Nacional dos Membros do Ministério Público de Defesa dos Direitos dos Idosos e Pessoas com Deficiência ${ }^{10}$ - tem como objetivo promover e defender os direitos dessas minorias.

Além do Ministério Público, a Defensoria Pública exerce importante papel na consolidação dos direitos de cidadania, de modo a contemplar os direitos que constam

\footnotetext{
${ }^{10}$ Disponível em www.ampid.org.br
} 
do Estatuto do Idoso. Em 2009, a Defensoria Pública da União, em parceria com os estados, lançou a campanha "Idosos, nós defendemos", através da qual articulou a divulgação por todo o país da cartilha "Defensor Público - Amigo do Idoso", divulgando os direitos dos idosos.

0 que fica evidente é que o país assistiu a um amplo e consistente processo de politização da justiça, através do qual se exigiu que o Estado se posicionasse frente às situações de violência sofridas pelas minorias discriminadas. No entanto, o que se verifica é que, na contramão dessa politização da justiça, corre-se o risco da judicialização das relações sociais, através da transformação da relação entre família e Estado. A dinâmica dos atendimentos nas delegacias aponta riscos nessa direção.

Em pesquisa realizada num município no interior do estado de São Paulo, Oliveira (2008) mostra que a quase totalidade das ocorrências registradas por pessoas de 60 anos ou mais nas delegacias investigadas é feita por indivíduos independentes, com alto grau de autonomia funcional, que podem ir às delegacias para realizar suas queixas. A autora articulou a análise da documentação produzida pela polícia à observação de comportamentos no ambiente policial, com a intenção de mapear os tipos de ocorrências e os perfis dos envolvidos nos registros, e contrastou a isso à maneira como os agentes compreendiam tais queixas na Delegacia de Defesa da Mulher (DDM) e no Distrito Policial (DP) do município investigado. 0 trabalho mostra que existem diferenças na maneira de encarar esses crimes nos dois tipos de delegacias e aponta para a feminização e para a invisibilidade que os crimes contra o idoso adquirem. Como disse um delegado:

Olha, eu já te adianto que tem muito pouco disso aqui, a quantidade é insignificante; porque tem mais desses casos com vítimas mulheres, que você vai achar na delegacia da mulher. Eu não sei se esse estatuto do idoso foi pouco divulgado, ou se o homem, por ser mais machista, não denuncia, mais aqui, olha, se eu te disser que tive um caso no ano passado inteiro foi muito [...] tem senhor que vêm dizendo que tinha sido empurrado pelos filhos, querendo denunciar; depois a gente descobre que ele que tinha caído sozinho, que ele que quer morar sozinho e fica dizendo que os filhos querem expulsá-lo de casa, e é assim, a gente nem liga muito (OLIVEIRA, 2008, p. 126).

A pesquisa mostrou uma constante reiteração da inexistência de ocorrências que tem o idoso como vítima feita pelos policiais entrevistados e revelou que das 2039 ocorrências registradas no distrito policial em 2004, a vítima em 63 dos Boletins de Ocorrência tinha 60 anos ou mais. Os agentes negavam a existência de denúncias envolvendo idosos no distrito, considerando que tais ocorrências só poderiam ser encontradas em delegacias especializadas em atendimento de mulheres, por se tratarem 
de problemas domésticos e familiares. Ao associar as ocorrências envolvendo idosos a um pólo feminino, representado pela delegacia de mulheres, os policiais operavam uma feminização de tais crimes e de suas vítimas, desconsiderando a existência de violência contra homens idosos.

0 trabalho de Oliveira (2008) evidenciou a centralidade da dimensão de gênero na discussão sobre a violência contra o idoso. Não se trata apenas de dizer que o número das mulheres com 60 anos ou mais é maior que o de homens, como tem sido apontado pelas estatísticas demográficas e reiterado pelos estudos sobre o tema. Do mesmo modo, não se pretende afirmar que as mulheres são majoritariamente as vitimas da violência contra os idosos, como os estudos sobre gênero e envelhecimento têm apontado. 0 que ficou evidente é que as convenções sobre a velhice presentes nas delegacias estudadas tendem a embutir nos homens idosos atributos femininos, ou então acabam por desclassificá-los da condição de idosos quando atributos tidos como próprios da masculinidade são identificados nos homens de 60 anos ou mais que recorrem à polícia - como são aqueles que possuem independência financeira e autonomia funcional.

0 Dossiê da Pessoa Idosa (2007), que apresenta um balanço das ocorrências com vítimas com 60 anos ou mais no Estado do Rio de Janeiro entre 2002 e 2006, mostra como a dimensão de gênero se articula de maneira complexa em relação à violência contra o idoso: no total de delitos investigados, os homens foram de modo geral as maiores vítimas (53,4\% de vítimas do sexo masculino contra 43,9\% de ocorrências com vítimas mulheres). No entanto, em alguns delitos específicos isso se inverte, como é 0 caso dos crimes contra a pessoa (49\% de vítimas mulheres e $47,7 \%$ de homens), crimes contra os costumes (82,5\% de vítimas mulheres e 12,5\% de homens), e estelionato (50,8\% de mulheres e $47,3 \%$ de vítimas do sexo masculino). Entre os delitos em que os homens idosos foram a maioria das vítimas se destacam os crimes contra o patrimônio, em que esses figuraram como vítimas em $54,8 \%$ das ocorrências, enquanto as mulheres o foram em $43,2 \%$.

A pesquisa de Oliveira (2008), em duas delegacias no interior de São Paulo, mostrou que as ocorrências envolvendo idosos ganhavam invisibilidade não apenas do Distrito Policial investigado, mas também entre os agentes da delegacia da mulher do mesmo município. Quando interrogados sobre ocorrências envolvendo idosos, os agentes da DDM concordavam com a consideração de que "aqui tem pouco... o que a gente tem são casos de gente da familia que rouba a aposentadoria do idoso... e os maus-tratos também.". Os agentes logo evocavam o crime de maus-tratos, expressando uma imagem do velho como um ser dependente, sem autonomia funcional. Para demonstrar solidariedade com os velhos, era também recorrente a aproximação do idoso com a criança pelo fato de ambos os grupos serem dependentes e vítimas de agressões tipificadas como maus-tratos. Como disse uma escrevente: "É complicado isso aí, porque coitadinhos, eles são indefesos, então ocorre os maus- 
tratos mesmo. São os dois extremos, os velhinhos e as crianças, os dois opostos que são dependentes, e por isso eles sofrem mesmo [...]".

A pesquisa na documentação revelou, no entanto, que das 2247 ocorrências registradas em 2006 em 90 casos a vítima tinha 60 anos ou mais.

Fica evidente que as convenções sobre gênero orientavam a maneira como a velhice estava associada, para os policiais das delegacias estudadas, a atributos ligados ao feminino e à infantilização. 0 ato de ir à delegacia em busca da resolução de seus conflitos parecia desconstruir, para os policiais, a imagem da fragilidade, da dependência e principalmente da impotência, a qual impediria um idoso de realizar tal ato - impotência que ocorreria, por exemplo, no crime de maus-tratos em que o idoso estivesse passivo e acamado.

Ao contrastar a visão desses policiais às informações obtidas através dos registros das ocorrências, Oliveira (2008) verificou a desconexão entre o que os agentes da Delegacia da Mulher e do Distrito Policial compreendiam como violência contra o idoso e aquilo que foi registrado pela parcela da população de 60 anos ou mais que recorreu àquelas delegacias no período investigado. Os dados estatísticos e a observação da pesquisadora em campo mostraram que existiram ocorrências nas delegacias investigadas, porém, não com o perfil da vítima esperado pelos policiais. 0 idoso que procurou a polícia para registrar eventos - tais como a perda de documentos ou outros bens ou declarou ser vítima de ameaças ou agressões - era um indivíduo ativo, independente, autônomo, proprietário de renda própria, muitas vezes até de bens imóveis, e não um ser dependente e fragilizado, tal como é, na percepção dos policiais, a imagem do idoso vítima de maus-tratos ou de negligência. A pesquisa mostrou que os idosos que recorriam às delegacias estudadas, em sua maioria, possuíam renda própria de aposentados e denunciavam principalmente ameaças e lesões corporais. No Distrito Policial investigado, 32\% das vítimas declaravam serem aposentadas, enquanto $18 \%$ tinham outras profissões e apenas 1\% era desempregada; na Delegacia de Defesa da Mulher, $57 \%$ das ocorrências eram com vítimas aposentadas, enquanto 9\% eram domésticas, 3\% costureiras e apenas 15\% alegavam serem "do lar" (OLIVEIRA, 2008).

Em relação ao tipo de ocorrência mais registrado nas delegacias investigadas foram as ameaças, com 14\% das ocorrências do Distrito Policial e 24\% das ocorrências da Delegacia da Mulher. As lesões corporais dolosas compuseram boa parte das ocorrências, com $12 \%$ dos registros nas duas delegacias. 0 crime de maus-tratos, muito associado à criminalidade que atinge os mais velhos, atingiu apenas $2 \%$ dos registros de ocorrência do Distrito Policial e 6\% das ocorrências da Delegacia da Mulher (OLIVEIRA, 2008).

0 que fica evidente é que a estrutura de funcionamento da instituição policial faz com que as delegacias sejam procuradas justamente por aquelas pessoas que podem 
circular no meio urbano sem a ajuda de cuidadores. Evidentemente, os casos de maustratos contra idosos doentes e com grau elevado de dependência dependerão de terceiros para serem denunciados - o que ocorre com pouca frequência. Além disso, os trabalhos que apontam para o perfil mais frequente dos agressores torna a questão ainda mais delicada. Embora a maioria dos documentos nacionais e internacionais que tratam a questão do envelhecimento, e inclusive da violência contra o idoso, coloquem a família como instância privilegiada no cuidado de seus membros mais velhos, as pesquisas mostram que, na instituição policial, são justamente os familiares que aparecem como principais perpetradores de abusos, negligência ou abandono, como vemos nas tabelas a seguir retiradas do estudo de Oliveira (2008):

Quadro 1 - Relação indiciado/vítima - DP

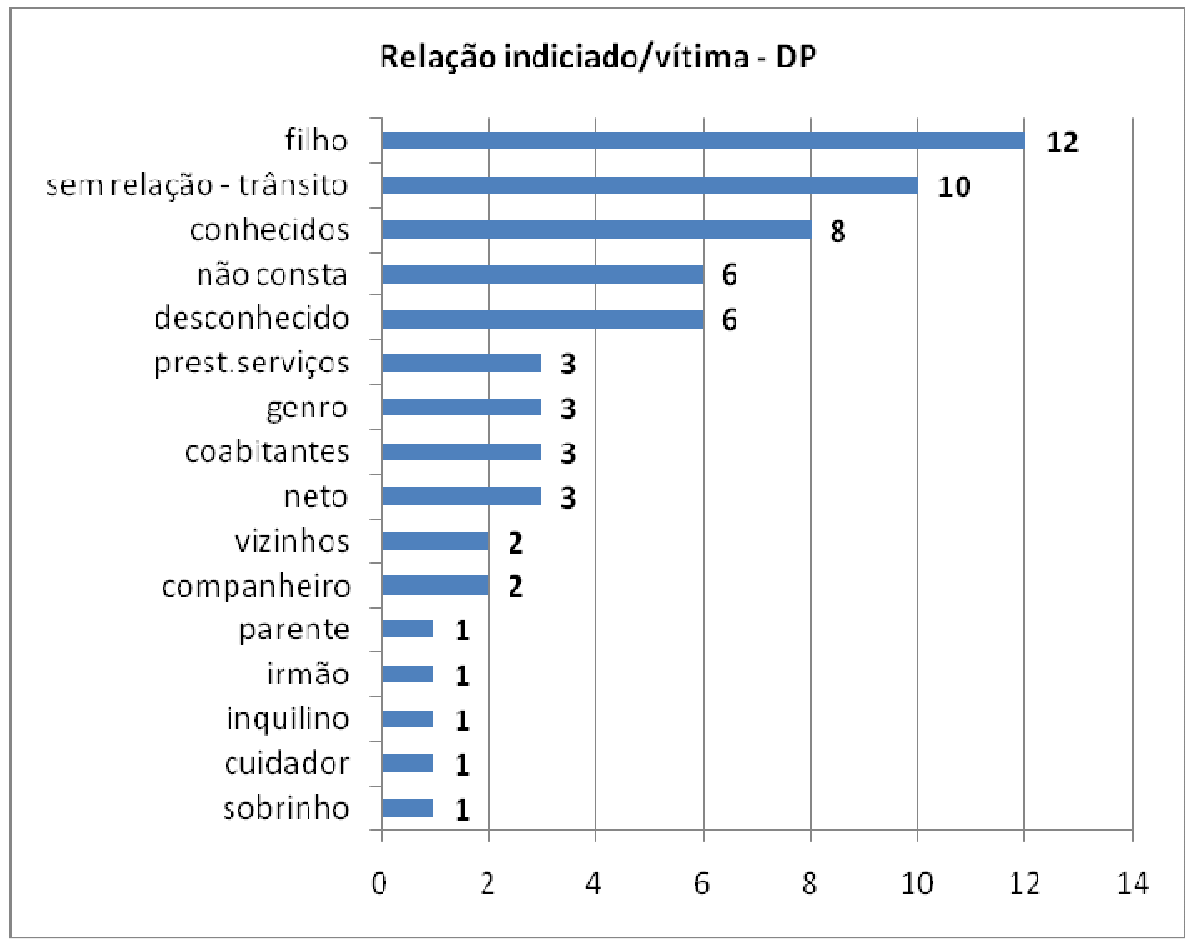

Fonte: Boletins de ocorrência registrados no $3^{\circ}$. Distrito Policial de Rio das Pétalas no ano de

\footnotetext{
${ }^{11} 0$ nome usado para identificar o município é fictício.
} 
Quadro 2 - Relação indiciado/vítima - DDM ${ }^{12}$

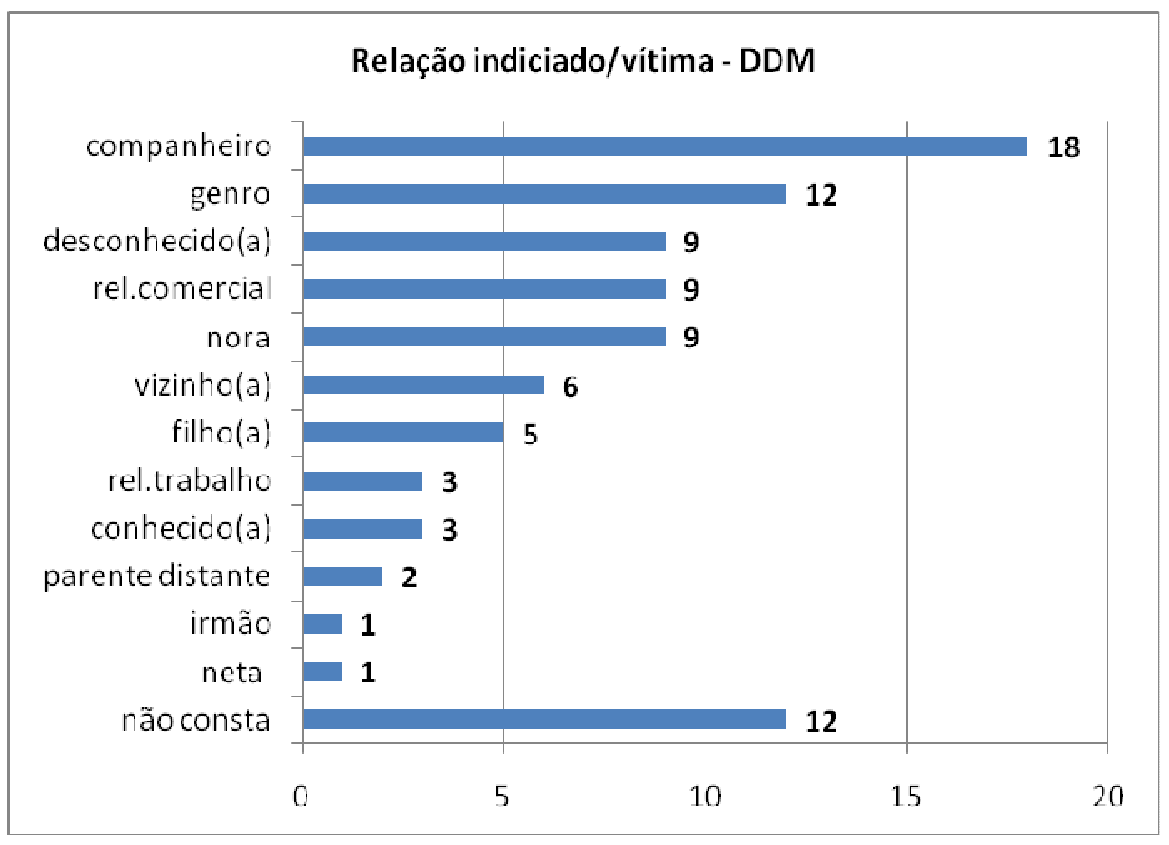
2006

Fonte: Boletins de ocorrência registrados na Delegacia de Defesa da Mulher de Rio das Pétalas em

0 Dossiê da Pessoa Idosa (2007) também aponta o fato de a maior parte dos delitos denunciados nas delegacias do Estado do Rio de Janeiro no período estudado terem sido praticados peloso parentes, companheiros e conhecidos, no interior das residências. Em relação ao crime de maus-tratos, os dados mostram que ele também não aparece de modo estatisticamente significativo $(0,3 \%$ do total de ocorrências registradas), sendo estes em sua maioria também praticados no interior das residências $(78,4 \%)$, por parentes ou conhecidos (55\%).

Nas Delegacias de Polícia de Proteção ao Idoso a situação não é muito diferente. Em pesquisa realizada nessas delegacias no início dos anos de 1990, Debert (2001) demonstra que a grande maioria das ocorrências registradas tinha como indiciado algum parente da vítima ${ }^{13}$.

\footnotetext{
${ }^{12} 0$ nome usado para identificar o município é fictício.

${ }^{13}$ Sobre violência contra o idoso, ver: Machado e Queiroz. (2002); Pasinato, Camarano e Machado (2004) e Peixoto (2011).
} 
0 número de denuncias de idosos contra seus familiares foi surpreendente para os agentes desse equipamento policial, já que estes, assim como ocorreu em relação ao GAEPI do Ministério Público, esperavam combater a violência perpetrada por instituições asilares e outros serviços voltados para a população mais velha. Outra constatação da pesquisa é que as vítimas não queriam a punição de seus agressores por se tratarem de seus próprios parentes, e por isso não davam prosseguimento aos procedimentos policiais.

Essa realidade foi percebida também na pesquisa realizada por Oliveira (2008), a qual mostra que parte significativa das ocorrências registradas por pessoas de 60 anos ou mais tinha como indiciados familiares ou coabitantes das vítimas. No DP os familiares e coabitantes representaram $51 \%$ dos indiciados, enquanto na DDM esses foram os acusados em $54 \%$ dos boletins registrados. 0 que a autora ressalta é que compostas essencialmente por conflitos entre familiares e conhecidos, as ocorrências registradas pelos idosos nessas delegacias estão entre o conjunto de denúncias que os policiais desqualificavam. Há um forte descontentamento associado à idéia de que o tipo de trabalho que essas ocorrências exigem está mais ligado a uma função de assistente social do que propriamente de polícia. Isso se dá, principalmente, em função de que, pelo fato dos envolvidos nesse tipo de ocorrência serem familiares ou conhecidos, raramente as vítimas queriam processar penalmente seus agressores. Assim como Debert (2001) constatou na pesquisa na Delegacia do Idoso em São Paulo, a pesquisa de Oliveira (2008) também identificou que as vítimas esperavam que a polícia atuasse como um freio à conduta violenta, conciliando as partes, dando um "susto", ou até "aconselhando" o agressor para que se restabelecesse 0 vínculo familiar.

Sem dúvida, a ida do idoso até a delegacia para registrar uma ocorrência, além de desconstruir a imagem de fragilidade associada à velhice pelos policiais, como mostra Oliveira (2008), revela uma capacidade de agência desses indivíduos, ao passo que esses policiais associariam à impotência das vítimas a necessidade de sua intervenção. 0 velho passivo e sem vigor físico não vem às delegacias registrar ocorrências, e por isso 0 número de situações que poderiam ser tipificadas como maus-tratos não ser representativo. A violência contra esse idoso raramente chega ao conhecimento da polícia, e só se revela em situações extremas e quando a mídia se dispõe a dar publicidade a elas. Na medida em que todos sabem que a polícia não dispõe de abrigos ou de uma estrutura que ofereça espaços para encaminhar e acolher idosos agredidos por familiares ou mesmo vítimas de maus tratos em instituições asilares, a delegacia será fatalmente procurada apenas por aqueles idosos que esperam que a polícia possa intimidar seus parentes ou vizinhos. A ausência de uma estrutura capaz de garantir os direitos dos idosos e com presteza proteger as vítimas dos vários tipos de violência dá assim uma dinâmica específica ao funcionamento das delegacias de polícia, às queixas que nela são apresentadas e ao perfil das vítimas e de seus agressores. 
Certamente é preciso, por outro lado, também reconhecer que a família não pode ser considerada um espaço de carinho e proteção. No pós-guerra, como mostra Simon Biggs (1996), as ideologias e práticas do Welfare State tinham um conteúdo paternalista que impedia o questionamento da integridade da família como instância privilegiada para arcar com o cuidado de seus membros. Esse paternalismo é abalado nos anos de 1970, com os movimentos de denúncia da violência doméstica contra a criança, a mulher e 0 idoso. Contudo, não se pode transformar a violência contra 0 idoso em mais uma expressão exclusiva da violência doméstica e as delegacias de polícia numa instância de reconciliação da família ou de imposição de normas sobre como filhos e netos adultos devem tratar seus pais idosos.

As delegacias de proteção ao idoso, bem como as demais políticas públicas voltadas a combate da violência contra 0 idoso, são expressão de um processo de politização da justiça e não podem correr o risco de se verem transformadas em instâncias encarregadas da judicialização de relações sociais.

\section{JUDICIALIZAÇÃO DAS RELAÇÕES SOCIAIS E A FAMÍLIA MALOGRADA}

Pesquisas de cunho quantitativo têm mostrado que a violência contra o idoso tem sido associada, pelos mais velhos, a problemas de ordem política e sociocultural e não à violência doméstica ou familiar. No levantamento que realizaram sobre o tema, Pasinato, Camarano e Machado (2004) mostram que a percepção dos idosos sobre o que é maus-tratos na velhice tem significados distintos em diferentes países da América Latina. Pesquisas realizadas na Argentina e no Chile indicaram uma prevalência da percepção de maus-tratos na esfera micro/intrafamiliar, como agressividade, falta de respeito, negligência e abandono e apenas uma minoria identificou a violência contra os idosos com questões sociais e econômicas.

No Brasil, 65\% dos idosos consideraram que a violência está na forma preconceituosa como são tratados os velhos pela sociedade em geral (os baixos valores das aposentadorias, o desrespeito nos transportes públicos, a falta de leitos hospitalares, etc.). Dentre os aspectos micros, ressaltaram apenas o abandono dos idosos por parte das famílias. Essa percepção de violência pelos idosos brasileiros foi também encontrada em outra pesquisa realizada no Rio de Janeiro (MACHADO; QUEIROZ, 2002). Os homens idosos declararam como primeiro sintoma de violência os baixos valores dos benefícios previdenciários. As mulheres, por sua vez, elegeram os maus tratos sofridos nos meios de transporte como a principal fonte.

Os dados sobre as delegacias de proteção ao idoso e de outros serviços de combate a esse tipo de violência indicam, pelo contrário, que é a agressão dos familiares que 
ganha destaque entre as denúncias registradas. Nesse sentido, a violência contra o idoso passa a ser expressão da "violência doméstica".

Ao operar a conciliação familiar, as delegacias se transformam em instituições promotoras da judicialização de relações familiares. Com a expressão juridicização ou judicialização das relações sociais, vários autores chamam a atenção para a crescente invasão do direito na organização da vida social. Nas sociedades ocidentais contemporâneas, essa invasão do direito não se limita à esfera propriamente política, mas tem alcançado a regulação da sociabilidade e das práticas sociais em esferas tidas, tradicionalmente, como de natureza estritamente privada, como são os casos das relações de gênero e o tratamento dado às crianças pelos pais ou aos pais pelos filhos adultos.

Os novos objetos sobre os quais se debruça o Poder Judiciário compõem uma imagem das sociedades ocidentais contemporâneas como cada vez mais enredadas com a semântica jurídica, com seus procedimentos e com suas instituições.

Alguns analistas consideram essa expansão do direito e de suas instituições ameaçadora da cidadania e dissolvente da cultura cívica, na medida em que tende a substituir o ideal de uma democracia de cidadãos ativos por um ordenamento de juristas que, arrogando-se a condição de depositários da ideia do justo, acabam por usurpar a soberania popular. ${ }^{14}$ As delegacias especiais de polícia voltadas para a defesa de minorias são, no entanto, fruto de reivindicações de movimentos sociais e, por isso, poderiam ser vistas como expressão de um movimento inverso de politização da justiça. Indicariam, antes, um avanço da agenda igualitária, na medida em que expressam uma intervenção da esfera política capaz de traduzir em direitos os interesses de grupos sujeitos ao estatuto da dependência pessoal. Elas são fruto da ideia de que a universalidade dos direitos só pode ser conquistada se for contemplada à maneira específica que a discriminação, a exploração, a violência, a crueldade e a opressão incidem na experiência das diferentes minorias.

Mas, como se procurou mostrar, dada a precariedade do modo como esses aparatos policiais e jurídicos funcionam e dos recursos disponíveis, tendem a mobilizar um tipo específico de demanda que acaba por transformar a violência contra o idoso em mais uma manifestação da violência doméstica. Desse modo, vê-se reduzido o seu escopo de atuação que passa a ser, na prática, a de impor normas que devem reger as relações entre os idosos e seus cônjuges, filhos e netos.

Sabemos que gênero não é uma propriedade dos corpos, nem algo que existe a priori nos seres humanos, mas sim um conjunto de efeitos produzidos nos corpos e por

\footnotetext{
${ }^{14}$ Para um balanço deste debate ver Vianna (1999); sobre a judicialização dos conflitos conjugais ver Rifiotis (2003) e Habermas (1987).
} 
isso gênero tem que ser compreendido como relacional e performático. 0 que procuramos mostrar é que na contramão de fluxos globais que marcaram a primeira década do milênio pelo empenho em garantir direitos aos idosos e transformá-lo num sujeito político vemos o modo pelo qual a velhice, nas práticas policiais, pode passar um processo de feminização e de transformação do velho em objeto da violência familiar.

Como vimos, a velhice é feminizada nas delegacias na medida em que está associada a atributos femininos que desconsideram uma série de masculinidades e feminilidades possíveis, as quais se articulam de múltiplas maneiras nas relações de poder e hierarquia colocadas em jogo nas ocorrências apresentadas no dia-a-dia dessas instituições. Desse modo, tais ocorrências acabam por serem invizibilizadas, já que não correspondem às convenções de gênero, velhice e violência contra 0 idoso presentes nessas delegacias.

Assim, a rigidez dada às categorias "velhice" e "violência contra o idoso" associadas ao frágil e dependente, invariavelmente ligadas ao crime de maus-tratos cria espaços de deslegitimização que favorecem a invisibilização de outras múltiplas formas de violência contra velhos, tais como a violência contra homens idosos identificada pela pesquisa de Oliveira (2008) e pelo Dossiê da Pessoa Idosa (2007). Nesse sentido, velhos, mulheres e homens são pensados em lugares pré-estabelecidos dentro das relações, o que torna uma série de outras configurações de relações de poder e hierarquia fenômenos ininteligíveis.

Debert (2001) mostra como a construção dessa nova categoria de crimes englobados na expressão "violência doméstica", transforma concepções próprias da criminologia. As causas envolvidas na produção dos crimes são vistas como de caráter moral ou resultados da incapacidade dos membros da família de assumir os diferentes papéis que devem ser desempenhados em cada uma das etapas do ciclo da vida familiar. A família ganha novos significados. Não é mais a família patriarcal tal como esse modelo foi caracterizado no estudo sobre a família brasileira. ${ }^{15}$ Não se trata de um mundo privado impenetrável às instituições estatais e ao sistema de justiça. Estamos também muito distantes da família como o reino da proteção e da afetividade, o refúgio num mundo sem coração. A família passa a ser percebida como uma instância em que os deveres de cada um de seus membros são claramente definidos, e as políticas públicas devem criar mecanismos capazes de reforçar e estimular cada um deles no desempenho de seus respectivos papéis.

Assim, é fruto dos nossos paradoxos corrermos o risco de responsabilizar a família pela destituição humana e transformá-la em objeto privilegiado da ação policial e da ausência de reconhecimento dos direitos das minorias.

\footnotetext{
${ }^{15}$ Ver sobre o tema Corrêa (1981); (1983); Lins de Barros (1987).
} 


\section{REFERÊNCIAS}

BIGGS, Simon. Elder abuse in perspective: Buckingham. Philadelphia: Open University Press, 1996.

. Toward critical narrativity: stories of aging in contemporary social policy.

Journal of Aging Studies, Oxford, v. 15, n. 4, p. 303-316, 2001.

CORRÊA, Mariza. Os crimes da paixão. São Paulo: Brasiliense, 1981.

. Morte em familia: representações jurídicas e papéis sexuais. Rio de Janeiro: Graal, 1983.

DEBERT, Guita Grin. A reinvenção da velhice. São Paulo: FAPESP/EDUSP, 1999.

. A família e as novas políticas sociais no contexto brasileiro. Intersecções:

Revista de Estudos Interdisciplinares do Programa de Pós-Graduação em Ciências Sociais da UERJ, Rio de Janeiro, ano 3, n. 2, p. 71-92, 2001.

DEBERT, Guita Grin; OLIVEIRA, Amanda. 0 idoso, as delegacias e os usos da violência doméstica. In: MORAES, Aparecida; SORJ, Bila (Org.). Gênero, violência e direitos na sociedade brasileira. Rio de Janeiro: 7 Letras, 2009. p. 23-48.

FOUCAULT, Michel. Vigiar e punir: a história da violência nas prisões. 16. ed. Petrópolis: Vozes, 1977.

HABERMAS, Jürgen. Tendências da juridicização. Sociologia, n. 2, p. 185-204, 1987.

JuVÊNCIO, Fernanda; BAPTISTA, Vanessa. As delegacias de proteção ao idoso em São Paulo e Campinas. Relatório de Iniciação Científica enviado ao CNPq em 1994.

KANT DE LIMA, Roberto; AMORIM, Maria Stella, BURGOS, Marcelo. L'administration de la violence quotidienne au Brésil: l'expérience des tribunaux criminels spécialisés.

Nanterre. L'Harmattan, Paris, n. 3, p. 199-228, 2001. (Numéro hors de serie).

LASLETT, Peter. The emergence of the third age. Aging and Society, Cambridge, v. 7, n. 2, 133-160, 1987.

LINS DE BARROS, Miriam Moraes. Autoridade e afeto: filhos e netos na família brasileira. Rio de Janeiro: Zahar, 1987.

LENOIR, Remi. Objet sociologique et probleme social. In: LENOIR; Remi; PINTO; Louis; CHAMPAGNE, Patrick; MERLLIE, Dominique (Org.). Initiation a la pratique Sociologique. Paris: Dunod, 1989.

MACHADO, Laura; QUEIROZ, Zally. Negligência e maus-tratos. In: FREITAS, Elizabeth Viana de; XAVIER, Flávio Aluizio (Org.). Tratado de Geriatria e Gerontologia, Rio de Janeiro: Guanabara-Koogan, 2002. p. 791-797. 
MIRANDA, Ana Paula; MELLO, Kátia Sento Sé (Org.). Dossiê da pessoa idosa. Rio de Janeiro: ISP, 2007. (Série Estudos, 5). Disponível em:

$<$ http://urutau.proderj.rj.gov.br/isp_imagens/Uploads/DossiePessoaIdosa.pdf > . Acesso em: 6 ago. 2012.

MOTTA, Alda Brito de. As dimensões de gênero e classe social na análise do envelhecimento. Cadernos Pagu, São Paulo, n. 13, p. 191-221, 1999.

OLIVEIRA, Amanda Marques. A feminização da velhice e a invisibilidade da violência contra o idoso. 2008. Dissertação (Mestrado em Antropologia Social) - Instituto de Filosofia de Filosofia e Ciências Humanas da Universidade Estadual de Campinas, Campinas.

PASINATO Maria Teresa; CAMARANO, Ana Amélia; MACHADO, Laura. Idosos vítimas de maus-tratos domésticos: estudo exploratório das informações dos serviços de denúncia. In: ENCONTRO NACIONAL DE ESTUDOS POPULACIONAIS, 14., 2004, Caxambu. Anais... Caxambú: ABEP, 2004.

PEIXOTO, Clarice. Sobre a institucionalização da velhice e as condições de asilamento. In: GOLDEMBERG, Miriam (Org.). Corpo, velhice e felicidade. Rio de Janeiro: Civilização brasileira, 2011.

RIFIOTIS, Theophilos. As delegacias especiais de proteção à mulher no Brasil e a "judicialização" dos conflitos conjugais. In: ANUÁRIO 2003: Direito e globalização. Rio de Janeiro: Lúmen Júris/UNESCO/MOST, 2003. p. 381-409.

RIFIOTIS, Theophilos.; CASTELNUOVO, Natália. La "violência" como punto de partida. In: . Antropologia, violência y justicia. Buenos Aires, Editorial Antropofagia, 2011.

VIANNA, Luiz Werneck; CARVALHO, Maria Alice Rezende de; MELO, Manuel Palacios Cunha; BURGOS, Marcelo Baumann. A judicialiazação da política e das relações sociais no Brasil. Rio de Janeiro: Renavan, 1999.

SIMÕES, Julio Assis. Provedores e militantes: imagens de homens aposentados na família e na vida pública. In: PEIXOTO, Clarice (Org.). Familia e envelhecimento. Rio de Janeiro: Editora FGV, 2004. p. 25-56. 